\title{
Out of regulatory limbo, 23andMe resumes some health tests and hopes to offer more
}

US regulators allow firm to market a limited number of carrier-status tests to consumers.

Erika Check Hayden

27 October 2015

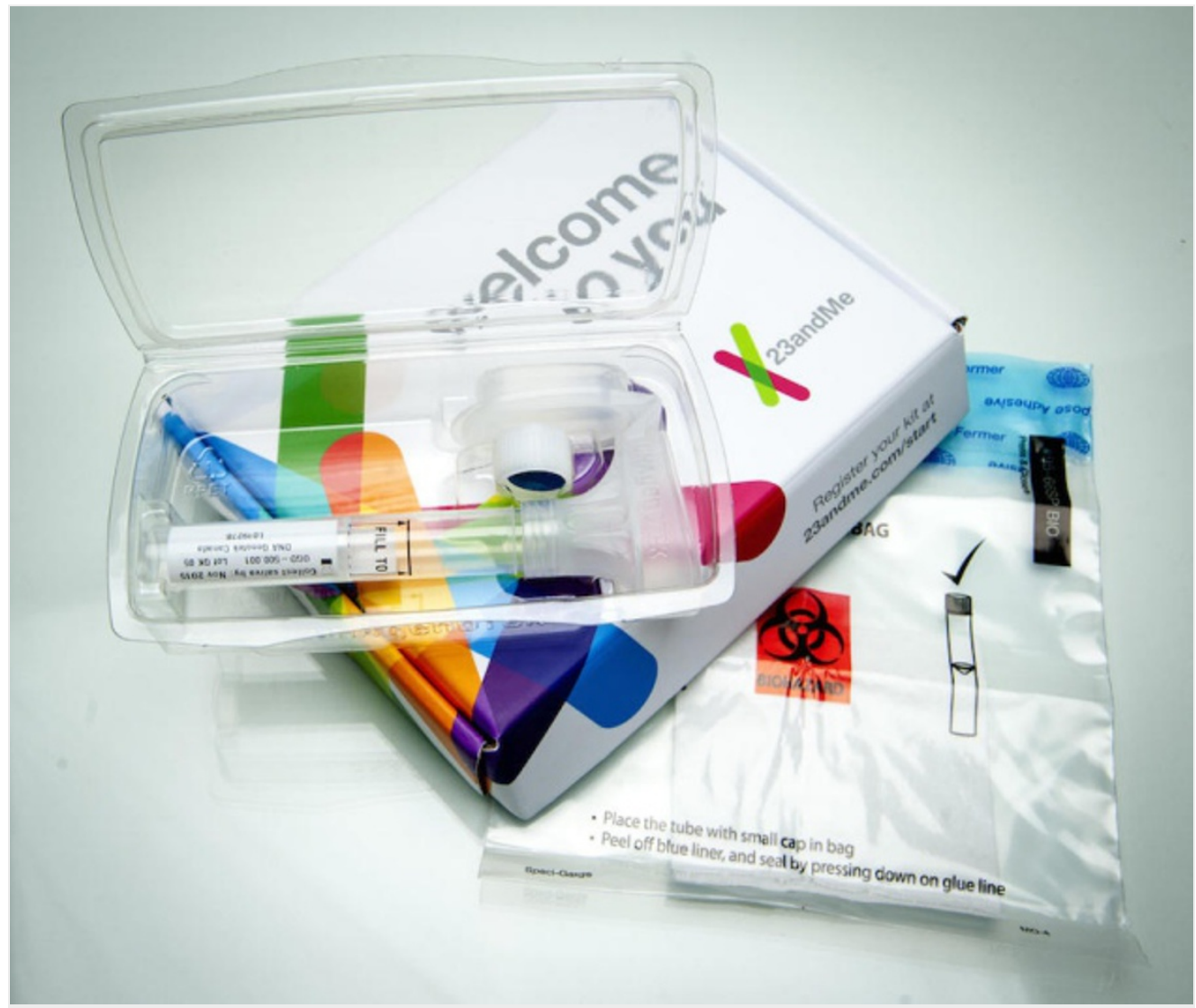

Zuma Press, Inc./Alamy

23andMe markets genetic testing directly to consumers.

As DNA-testing firm 23andMe resumes selling health-related services in the wake of a regulatory shutdown, the company says that it remains committed to its original business plan of providing genetic information directly to consumers. It plans to work with the US Food and Drug Administration (FDA) to expand its offerings. 
such as cystic fibrosis and $\beta$-thalassaemia. Before the FDA shut down its health business in November 2013, the company had offered consumers genetic testing to estimate their risk for 240 health conditions, such as breast cancer and heart disease, for $\$ 99$. During the nearly two-year ban, 23andMe continued to provide consumers with information about non-medical traits such as ancestry.

\section{In from the cold}

The company says that it will keep pushing to offer more health testing to consumers, despite the FDA's concerns about the accuracy and usefulness of such information.

"It's going to be an ongoing discussion with the FDA about the proper path forward," says 23andMe spokesperson Angela Calman-Wonson.

David Mittelman, a geneticist and entrepreneur based in Houston, Texas, calls the 23andMe relaunch "a milestone for consumer genetics".

But the company's retooled product also shows that using genes to predict customers' disease risks is not completely ready for prime time, observers say, because the science of genetics is not advanced enough to enable good predictions of the risk for most diseases based on genetics.

"They are still a long way away from getting back to where they were, returning results about people's relative lifetime risks of developing various deleterious health conditions," says Michelle Meyer, a bioethicist and legal scholar at the Icahn School of Medicine at Mount Sinai in New York.

\section{Plan B}

The company's revised test focuses on genetic glitches in customers' DNA that might cause 36 different diseases in their offspring. This type of information — 'carrier status' — is not intended to tell the customer anything about his or her own health.

The FDA first allowed 23andMe to offer a carrier test in February, for Bloom Syndrome. Other companies that offer such tests directly to consumers, such as Counsyl of South San Francisco, California, still require a doctor to approve the results.

And though 23andMe still offers testing for four traits related to "wellness", such as lactose intolerance, it warns consumers that its tests "are not intended to diagnose a disease, or tell you anything about your risk for developing a disease in the future".

"They are relaunching with one-quarter of their initial tests, including precisely none involving the customer's personal health situation, and they are charging twice as much," says Hank Greely, lawyer and bioethicist at Stanford Law School in California.

The consumer genetic testing landscape has also changed since late 2013. Other firms offer similar direct-to-consumer genetic testing, and 23andMe itself has branched out into drug development.

Still, Calman-Wonson says that consumer testing — which has attracted more than a million customers — "is always going to be at the core of our business model." As it grows larger, 23andMe's customer database becomes more valuable for research and drug development by the company and its partners, such as California-based biotechnology firm Genentech.

Nature I doi:10.1038/nature.2015.18641

Nature ISSN0028-0836 ESSN1476-4687

\section{SPRINGER NATURE}

(C) 2019 Macmillan Publishers Limited, part of Springer Nature. All Rights Reserved. partner of AGORA, HINAR, OARE, INASP, CrossRef and COUNIER 